\section{Lixo, trabalho e saúde: um estudo \\ de caso com catadores em um aterro metropolitano no Rio de Janeiro, Brasil}

\author{
Garbage, work, and health: \\ a case study of garbage pickers at the \\ metropolitan landfill in Rio de Janeiro, Brazil
}

\author{
1 Escola Nacional de Saúde \\ Pública, Fundação Oswaldo \\ Cruz, Rio de Janeiro, Brasil. \\ 2 Instituto de Ciências da \\ Sociedade e Desenvolvimento \\ Regional, Universidade \\ Federal Fluminense, Campos \\ dos Goytacazes, Brasil. \\ 3 Secretaria Municipal \\ do Bem-estar Social, \\ Prefeitura de Rio das Ostras, \\ Rio das Ostras, Brasil. \\ ${ }^{4}$ Núcleo de Estudos de Saúde \\ Coletiva, Universidade \\ Federal do Rio de Janeiro, \\ Rio de Janeiro, Brasil. \\ Correspondência \\ M. F. S. Porto \\ Centro de Estudos em Saúde \\ do Trabalhador e Ecologia \\ Humana, Escola Nacional \\ de Saúde Pública, \\ Fundação Oswaldo Cruz. \\ Av. Leopoldo Bulhões 1480, \\ Rio de Janeiro, $R J$ \\ 21041-210, Brasil. \\ firpo@ensp.fiocruz.br
}

\begin{abstract}
This article presents the results of a study on the lives, work, and health conditions of garbage pickers in the largest metropolitan landfill in Rio de Janeiro, Brazil. Using a semi-structured questionnaire with open-ended and closed questions, the study interviewed these individuals and developed a discussion of their daily lives, work, and health conditions. According to a quantitative-qualitative analysis, the garbage pickers identified garbage as a source of survival and defined health simply as the ability to work. They thus tended to neglect the relationship between work and health. However, the risks and reported morbidity highlighted the hazardous nature of this activity, aggravated by their living and housing conditions. Finally, the article emphasizes the importance of establishing public policies that integrate different dimensions of the problem, such as social inclusion, environmental preservation, public health, and the dignity of these workers.
\end{abstract}

Garbage; Occupational Health; Working Conditions
Marcelo Firpo de Souza Porto 1

Denise Chrysóstomo de Moura Juncá 2

Raquel de Souza Gonçalves 3

Maria Izabel de Freitas Filhote 4

\section{Introdução}

O cotidiano dos sujeitos que vivem da reciclagem do lixo ainda é pouco trabalhado pela saúde pública brasileira. Entre os 18 artigos levantados em revistas indexadas na base de dados SciELO (Scientific Electronic Library Online http://www.scielo.br) entre 1990 e 2003, nenhum analisa especificamente tal questão. A maioria versa sobre impactos gerais ou específicos do lixo sobre a saúde pública $1,2,3$; sobre a saúde dos trabalhadores do serviço de coleta de lixo 4,5; ou ainda sobre os impactos mais gerais das condições sociais e de vida, que incluem o lixo, sobre a saúde pública $6,7,8$. Por sua vez, a associação lixo-trabalho-exclusão social vem sendo abordada por autores como Araújo 9, Portilho 10, Escurra 11, Azeredo 12, Grossi 13, Juncá et al. 14, bem como já estão surgindo textos que analisam as perspectivas que se abrem em nível de formação de cooperativas e associações de catadores, como é o caso de Muñoz 15 e Magera 16. Tais trabalhos, contudo, não aprofundam questões de interesse para a saúde pública.

Este artigo visa reduzir tal lacuna tendo por base empírica o projeto integrado de pesquisa intitulado Resíduos, Degradação Ambiental e Saúde: Uma Pesquisa na Baixada Fluminense, do Centro de Estudos em Saúde do Trabalhador e Ecologia Humana, Escola Nacional de Saúde Pública, Fundação Oswaldo Cruz (CESTEH/ ENSP/FIOCRUZ), que contou com a coopera- 
ção de pesquisadores da Universidade Federal do Rio de Janeiro (UFRJ) e da Universidade do Estado do Rio de Janeiro (UERJ), bem como da Universidade Popular da Baixada (organização não-governamental local que viabilizou contatos com movimentos sociais e prefeituras da região).

$\mathrm{O}$ artigo encontra-se estruturado em quatro partes principais. Inicialmente, são tecidas considerações metodológicas sobre a investigação realizada, seguida de informações sobre a história do Aterro de Jardim Gramacho e o processo de trabalho dos catadores. A parte central do artigo destaca alguns resultados mais relevantes, e a discussão final aborda a complexidade do tema e a necessidade de que as políticas públicas integrem as diferentes dimensões do problema, incluindo o resgate da dignidade desse grupo social enquanto trabalhadores e cidadãos.

\section{Metodologia}

No período inicial da investigação (fevereiro de 2001), além de consultas a documentos e algumas entrevistas preliminares, buscou-se uma primeira aproximação com o cenário da pesquisa através da visita aos diferentes locais onde se desenvolvia a atividade da catação, conhecendo-se melhor seus grupos e processos de trabalho. O número de entrevistados representou cerca de $20,0 \%$ do universo de catadores, tendo por referência o cadastro existente no serviço social da empresa gestora e considerando as diferenças proporcionais existentes de sexo, faixa etária e situação de trabalho, as quais distinguiam três subgrupos - cooperados, cadastrados e vinculados aos depósitos - que serão mais bem explicados no próximo item.

A proposta do questionário foi construir um perfil geral desses catadores e, dessa forma, possibilitar uma maior aproximação com o "mundo do lixo". Considerando os objetivos da pesquisa, o instrumento central de coleta de dados - o questionário - foi elaborado mesclando informações objetivas e subjetivas, que, para efeito de análise, foram agrupadas em quatro partes principais: (1) dados gerais da população, condições de vida e moradia; (2) trabalho e renda; (3) problemas ambientais, de saúde e morbidade referida; e (4) perspectivas de vida: dificuldades, melhorias e sonhos. Além do questionário, foram aproveitadas as anotações feitas pelos pesquisadores em seus diários de campo. Foram realizados dois testes pilotos, com trabalhadores de limpeza da FIOCRUZ e posteriormente com os próprios trabalhadores do aterro, que propiciaram algumas modificações visando melhorar o entendimento de alguns tópicos e facilitar a futura digitação dos dados.

A divulgação da pesquisa junto aos trabalhadores contou com a colaboração de alguns funcionários do aterro, mas foi realizada principalmente pelos próprios pesquisadores de campo, distribuindo panfletos com esclarecimentos nos horários de entrada e/ou saída de serviço, procurando motivar a participação. As entrevistas foram realizadas junto à entrada do aterro com catadores voluntários, seguindo-se os critérios de distribuição dos vários subgrupos previamente definidos, com um tempo médio aproximado de aplicação de uma hora. A seleção dos entrevistados ocorreu de forma aleatória, com exceção de algumas lideranças do aterro (menos de 5,0\% da amostra) indicadas tanto por seus próprios companheiros de trabalho, quanto por alguns técnicos atuantes no local. O retorno dos resultados da pesquisa, compromisso previamente acordado, foi realizado oito meses após o final do trabalho de campo, através da distribuição aos trabalhadores de folders com linguagem simplificada e um relatório mais detalhado para as instituições envolvidas, inclusive a cooperativa de catadores local.

\section{O aterro de Jardim Gramacho e o processo de trabalho dos catadores}

O Aterro Metropolitano de Gramacho, localizado no bairro de Jardim Gramacho (Município de Duque de Caxias, Rio de Janeiro, Brasil) e em operação desde 1976, é o principal ponto de destinação dos resíduos gerados na Região Metropolitana do Rio de Janeiro, atendendo aos municípios do Rio de Janeiro, Duque de Caxias, Nilópolis, São João do Meriti e Nova Iguaçu 17. No final dos anos 90, esse aterro recebia cerca de 6 mil toneladas de lixo diariamente.

Inicialmente projetado para ser um aterro sanitário, vários problemas impediram que esse objetivo se concretizasse, e o local funcionou basicamente como um vazadouro até meados dos anos 90. Desde seu início, constituiuse como espaço para o trabalho de diversos catadores eventuais e permanentes, além de propiciar o desenvolvimento de várias empresas de sucata nas redondezas. Dois fatores parecem ter tido relevância na mudança de gestão e na transformação do local num aterro mais adequado: (1) a crescente preocupação com os problemas ambientais do vazadouro, foco de proliferação de vetores, de degradação de manguezais e das águas da Baía de Guanabara 17,18, 
além de estar na origem de incidentes com urubus e aviões trafegando próximo ao Aeroporto Internacional Antônio Carlos Jobim, amplamente noticiados na imprensa; (2) o posicionamento mais crítico por parte das autoridades de Duque de Caxias, município industrial e periférico da Região Metropolitana do Rio de Janeiro. À época da criação do aterro, nos anos 70, o município era de segurança nacional, mas, com o processo de democratização, várias forças municipais se posicionaram contra o uso do solo local como depósito de lixo de outras cidades. Por fim, o Ministério Público também iniciou um processo para a solução do problema.

Como resposta a tais pressões, principalmente a partir de 1996, a Companhia Municipal Urbana do Rio de Janeiro (COMLURB), após terceirizar a gestão do aterro à empresa Queiroz Galvão, passou a investir na tentativa de transformar o mesmo efetivamente em aterro sanitário. Isso implicaria no tratamento do chorume produzido, na cobertura num período máximo de 24 horas do lixo depositado, e várias outras medidas de contenção que impedissem a destruição do manguezal e a contaminação das águas da Baía da Guanabara.

O caso do aterro de Gramacho é bastante singular, pois, teoricamente, segundo o paradigma da engenharia sanitária, não deveria comportar trabalhadores circulando pelas montanhas formadas pelo lixo. O plano inicial das instituições envolvidas era retirar os catadores das chamadas rampas de trabalho, ou seja, dos locais a céu aberto onde os caminhões depositam o lixo a ser posteriormente espalhado e coberto com terra pelos tratores. Ao mesmo tempo, foi estruturado um projeto para a criação de uma central de reciclagem com esteiras mecânicas a ser operada por uma cooperativa de catadores. Esses planos, contudo, foram modificados por um movimento de resistência dos catadores locais. Depoimentos relatam que, nessa época, foi feito um cordão humano e impedida a entrada de caminhões, o que causou um grande transtorno. Após negociações entre várias autoridades estaduais e municipais, foi forjado um acordo que permitiu a permanência dos catadores nas rampas de trabalho e implantado um sistema de controle para os catadores que quisessem continuar a trabalhar na rampa. O número de catadores no local foi limitado, bem como proibida a entrada de menores, idosos e catadores eventuais ou de alimentos, esses últimos chamados de podrão pelos próprios catadores. Durante a investigação, contudo, verificou-se que tal sistema de controle não funcionava completamente.
Com isso, na prática, passaram a existir dois locais de trabalho de catação: (1) o das linhas de triagem com esteiras mecânicas, localizado na entrada do aterro envolvendo os trabalhadores de uma cooperativa criada para esse fim com o apoio da COMLURB e da Queiroz Galvão; (2) e o junto à rampa, onde se encontrava a maioria dos catadores do aterro. Os que trabalhavam na rampa, por sua vez, podiam ser subdivididos em dois subgrupos: o de catadores cadastrados independentes e aqueles vinculados aos depósitos de sucata que comercializam o material reciclável.

A única relação que os trabalhadores da rampa possuíam com a empresa gerenciadora do aterro era o fato de serem cadastrados e controlados na entrada e saída, enquanto os trabalhadores da cooperativa possuíam uma relação bem mais intensa, em particular com o serviço social. Os cooperados dispunham de instalações como refeitórios, vestuário e banheiro, além da sala de administração da cooperativa. Além disso, a construção e boa parte da manutenção da unidade de triagem eram realizadas pela gerenciadora do aterro. Já os trabalhadores da rampa não possuíam nenhum tipo de apoio ou infra-estrutura, sendo freqüentemente referidos pelos técnicos das instituições como um problema que "não deveria existir e precisaria ser eliminado o mais brevemente". A contradição entre o paradigma gerencial da engenharia sanitária e a existência tolerada desses catadores, além de produzir diferenças e estigmas entre cooperados e catadores da rampa, repercutiu ao longo de todo o trabalho de campo, como na proibição de se fornecer lanche aos entrevistados.

\section{Resultados}

A seguir, apresentamos alguns dos resultados mais relevantes do inquérito. Os catadores são tratados como um grupo único, mas, no caso de questões cujos resultados apresentaram diferenças relevantes, os mesmos são subdivididos em dois grupos - cooperados e catadores da rampa.

\section{Dados gerais da população, condições de vida e moradia}

A população de catadores é formada basicamente por adultos jovens, embora com uma grande elasticidade na distribuição: dos 18 anos aos 75 anos. Na cooperativa, a média de idade é razoavelmente superior: 44 anos, contra 33 anos entre os da rampa. O percentual ge- 
ral de homens e mulheres é praticamente igual, porém, na cooperativa, a presença feminina encontrada foi bem superior $(71,4 \%)$, sob a alegação que o trabalho nas linhas de triagem exigiria menor esforço físico do que na rampa.

Quando a questão é o nível de escolaridade, quer se trate de homens ou mulheres, a maioria $(90,0 \%)$ sabe ler e escrever, embora $23,0 \%$ apontem dificuldades para tanto. É pequeno o índice daqueles que nunca estudaram $(6,8 \%)$, enquanto que mais de $90,0 \%$ chegaram a ingressar no ensino formal. Desse grupo, porém, apenas $6,4 \%$ concluíram o ensino fundamental, contra $1,8 \%$ que terminaram o ensino médio. A pesquisa registrou a existência de um catador que se encontrava cursando o ensino superior à época.

O Rio de Janeiro é o Estado de origem da maioria dos entrevistados: $72,5 \%$. Há, porém, $14,2 \%$ dos catadores que são naturais da Região Nordeste, e 11,9\%, de outros Estados da Região Sudeste. O principal local de moradia dos entrevistados é o próprio Município de Duque de Caxias com $78,5 \%$, sendo que boa parte $(43,4 \%)$ mora no próprio bairro do aterro. Os catadores entrevistados vivem, em média, há bastante tempo no mesmo bairro (15 anos) e na mesma casa (10 anos). São casas próprias em sua maioria $(79,0 \%)$, entendendo-se como próprias aquelas residências em que o dono é o entrevistado ou algum membro de sua família de origem (em geral os pais). Há também 9,1\% que moram em áreas de posse/invasão, e outros $9,1 \%$, em casas onde pagam um aluguel. $\mathrm{Na}$ mesma casa moram em média 4,3 pessoas, dispondo de 3,4 cômodos de alvenaria $(69,4 \%)$ ou madeira $(30,1 \%)$.

Entretanto, mais da metade $(51,4 \%)$ dos entrevistados gostariam de mudar para uma outra localidade, alegando principalmente as precárias condições tanto de suas casas, quanto em termos de infra-estrutura ambiental de seu bairro. As moradias encontram-se, em sua maioria $(68,0 \%)$, em ruas sem pavimentação, sendo que $50,0 \%$ dispõem da rede oficial de esgoto, mas um índice elevado encontra-se em outras situações: $23,6 \%$ fazem lançamento direto de seu esgoto, principalmente, em valas a céu aberto, e 19,0\% recorrem a fossas sépticas ou rudimentares. Tal fato se torna um problema ainda mais sério se considerarmos que $18,3 \%$ dos trabalhadores moram em casas cuja fonte d'água provém de nascentes ou poços, que podem estar sendo contaminados pelo esgoto. Com chuvas fortes ocorre também alagamento em $36,1 \%$ dos locais de moradia dos entrevistados.

Quanto à coleta de lixo domiciliar, 35,1\% das pessoas apontaram problemas, pois mo- ram em locais onde ela nunca ocorre ou acontece em período incerto ou inadequado. Em função disso, muitas pessoas $(31,5 \%)$ se vêem obrigadas a tomar providências como queimar o lixo ou lançá-lo em terrenos baldios ou em cursos d'água.

Quando não estão trabalhando, 55,2\% dos entrevistados descansam, enquanto que $42,0 \%$ se ocupam de atividades domésticas. Há, porém, $16,0 \%$ que fazem algum biscate, $8,7 \%$ que se dedicam a atividades religiosas, e $8,2 \%$ que se envolvem com esporte e lazer. Apenas $21,5 \%$ dos catadores mencionaram participar de alguma atividade em grupo, pondo em destaque o campo religioso e, em seguida, esporte, bailes e reuniões dos alcoólatras anônimos. Apenas uma pessoa mencionou participar da associação de moradores do local onde mora. Pequeno é também seu envolvimento em programas e benefícios sociais: apenas 7,3\% se referiram a algum tipo de auxílio, mas não o especificaram.

\section{Trabalho e renda: as diferenças} entre a cooperativa e a rampa

Meio de sobrevivência, possibilidade de conquistar uma independência, forma de distração e de fazer amigos, modo de se sentir útil, único jeito de conseguir as coisas honestamente - essas e outras tantas foram as respostas dadas pelos entrevistados ao serem perguntados sobre o sentido do trabalho em suas vidas. A maioria começou a trabalhar ainda quando criança, como mostra a Figura 1, exercendo atividades auxiliares às desenvolvidas por seus pais.

Com o tempo, passaram por várias ocupações tais como mecânicos, lanterneiros, pedreiros, pintores, pescadores, cozinheiras, costureiras, vigilantes, auxiliares de protéticos, balconistas e até artistas plásticos. Um número sem fim de profissões que foram deixando para trás para ingressarem no trabalho com o lixo. O desemprego foi o motivo mais marcante para a busca de uma ocupação no lixo. Entretanto, a necessidade de "ajudar em casa", complementando a renda dos familiares, foi um motivo que mereceu destaque entre aqueles que começaram a trabalhar ainda crianças.

A idade média em que o trabalho com o lixo passou a fazer parte da vida dos entrevistados foi de 24 anos. Entretanto, um número expressivo começou tal atividade antes dos 18 anos, conforme mostra a Figura 2. Para a maioria, esse começo ocorreu no próprio Jardim Gramacho $(76,2 \%)$, mas $18,3 \%$ vieram de outros aterros, 3,6\% iniciaram em depósitos de sucata, e apenas $1,4 \%$ são provenientes da ca- 
tação de rua. Entre os pesquisados, encontramos aqueles que começaram a trabalhar com o lixo há apenas três meses, e o que possui maior tempo já está em tal ocupação há 58 anos, com a média em torno dos dez anos. A Figura 3 ilustra a distribuição por faixa etária desse tempo, revelando um número expressivo de pessoas que persistem há mais de vinte anos nessa atividade.

Em termos dos rendimentos mensais informados pelos catadores no período da aplicação do questionário, encontramos uma variação de R\$ 100,00 a R\$ 1.300,00, embora a média mensal tenha sido de $\mathrm{R} \$ 363,00$, e a maioria das pessoas ganhem até $\mathrm{R} \$ 300,00$ como ilustra a Figura 4. O rendimento é um dos itens no qual se identificam diferenças significativas entre os cooperados e demais trabalhadores da rampa. Na cooperativa, a média detectada foi de $\mathrm{R} \$$ 223,00 , enquanto que, na rampa, ela atingiu $R \$$ 383,00 . Nessa última, ocorre uma certa variação entre os cadastrados autônomos (média de $\mathrm{R} \$ 408,00$ ) e os trabalhadores vinculados aos depósitos (média de R\$361,00). Cabe destacar que, na cooperativa, há uma concentração bem maior em torno da média, enquanto que, na rampa, essa variação é bem maior (valor mínimo de $\mathrm{R} \$ 100,00$ e máximo de $\mathrm{R} \$ 1.300,00$ ).

Observações de campo e conversas com catadores e técnicos no local indicam, como possíveis justificativas para essa grande variação, o tempo dedicado ao trabalho, a qualificação na atividade (escolha de materiais e rapidez na ca- tação) e o papel exercido quando da existência de pequenos grupos de trabalho. Possivelmente são as lideranças desses grupos que se encontram entre os quase $10,0 \%$ que ganham mais de $\mathrm{R} \$ 600,00$.

Para entender a diferença de renda entre a cooperativa e a rampa, um fator importante a ser considerado é o número de horas trabalha-

Figura 1

Faixa etária de ingresso na primeira atividade de trabalho dos catadores do aterro de Gramacho. Município de Duque de Caxias, Rio de Janeiro, Brasil.

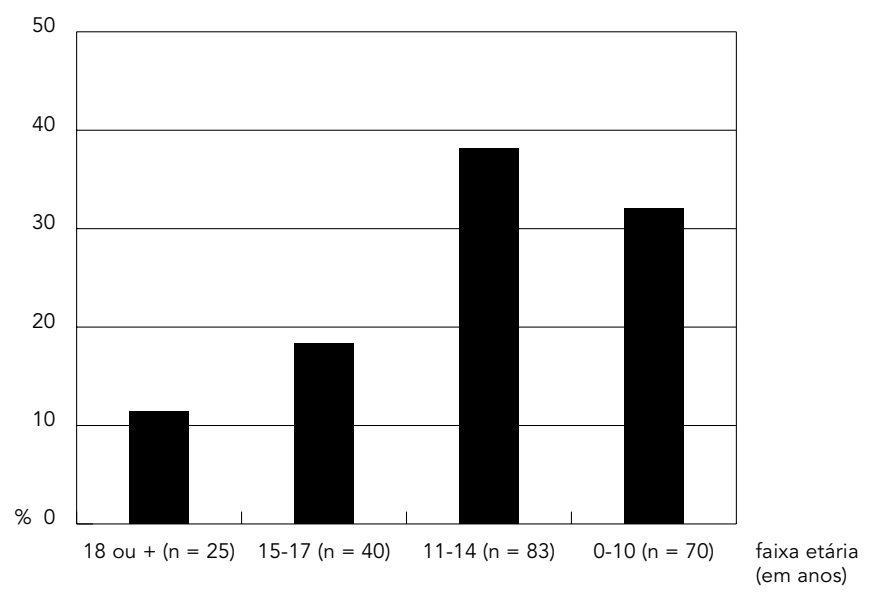

Figura 2

Faixa etária de ingresso no trabalho com reciclagem de lixo dos catadores do aterro de Gramacho.

Município de Duque de Caxias, Rio de Janeiro, Brasil.

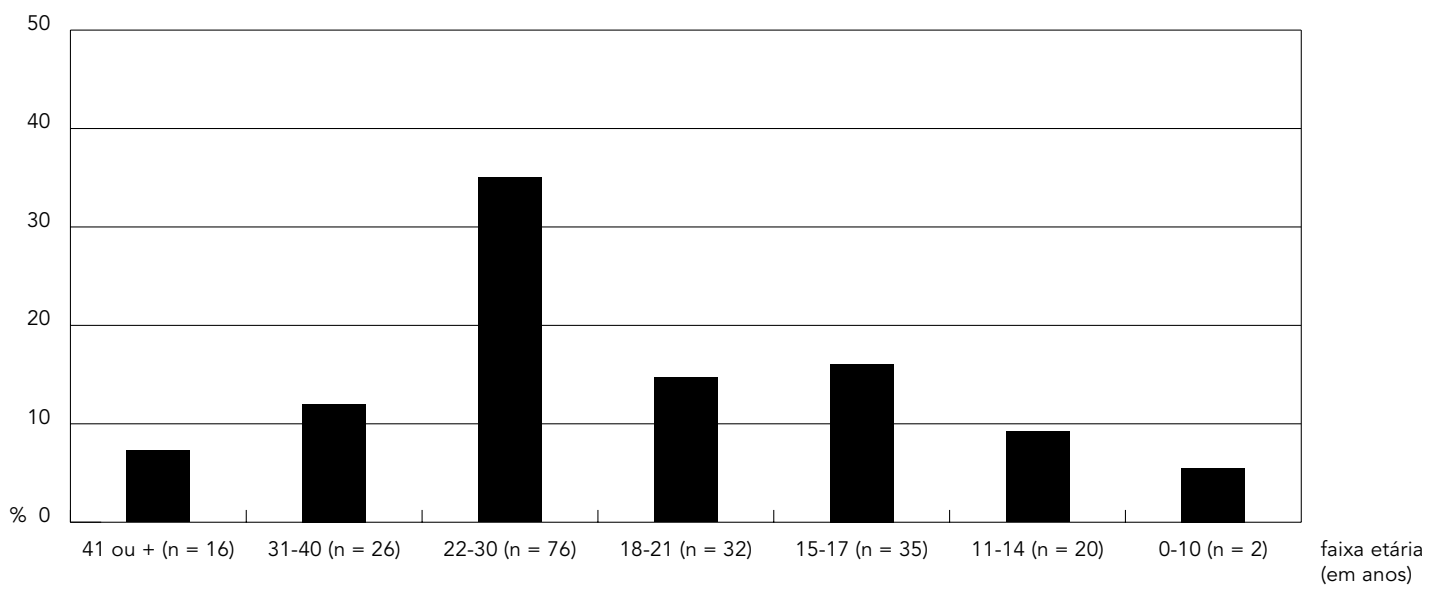


Figura 3

Distribuição do tempo de trabalho com lixo dos catadores do aterro de Gramacho.

Município de Duque de Caxias, Rio de Janeiro, Brasil.

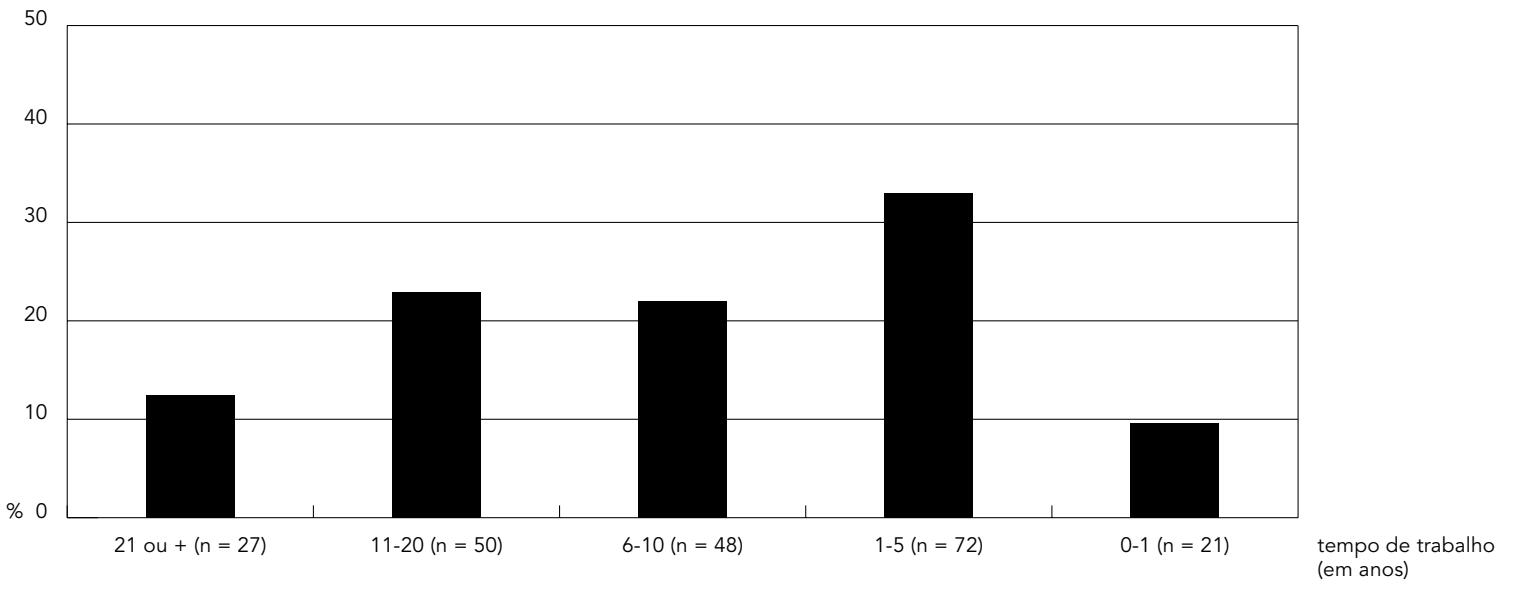

Figura 4

Distribuição dos rendimentos dos catadores do aterro de Gramacho.

Município de Duque de Caxias, Rio de Janeiro, Brasil, março a julho de 2001.

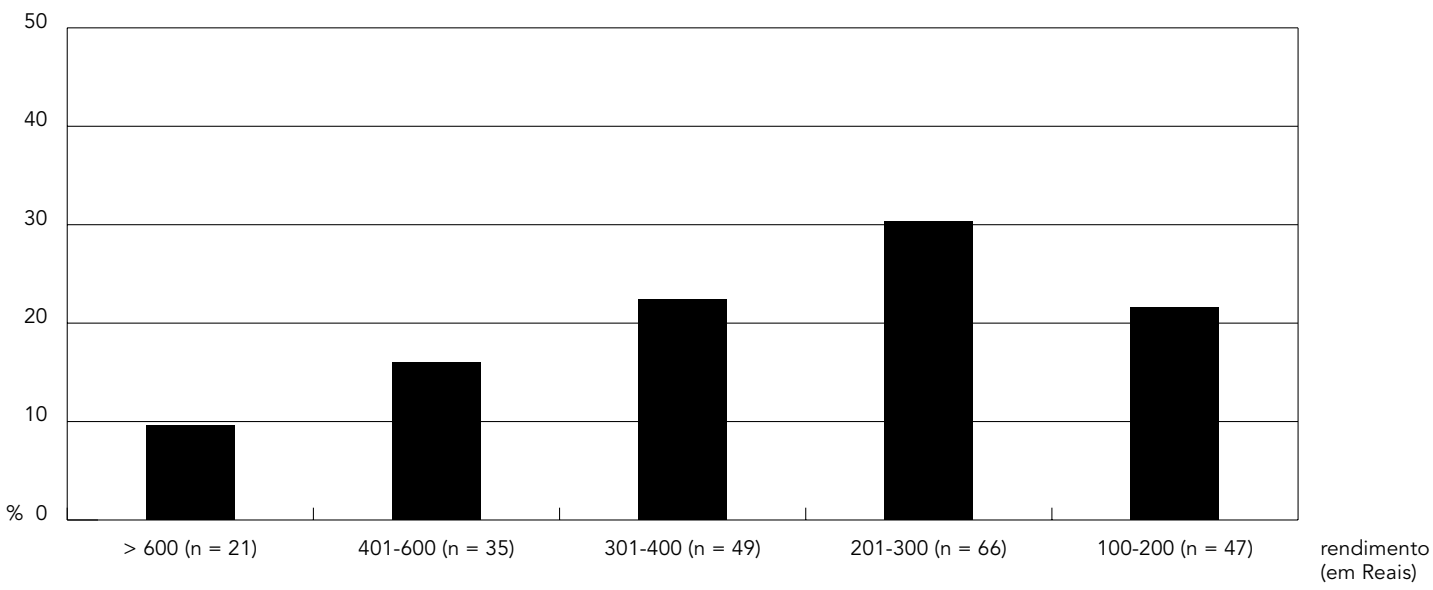


das: na rampa, encontramos uma média semanal bem superior à média da cooperativa $(46,7$ e 26,0 horas respectivamente). À época da pesquisa, o trabalho na cooperativa estava ocorrendo com turnos reduzidos em decorrência de reparos em um dos módulos de produção (esteira mecânica). Dessa forma, considerando a informação do rendimento obtida para aquele período, se comparamos o rendimento horário médio entre os dois locais de trabalho, verificamos um valor similar em torno de $\mathrm{R} \$ 2,10$.

Apesar da diferença de rendimentos, a maioria dos entrevistados afirmou que sua preferência é continuar mantendo sua atual situação de trabalho, sejam os cooperados $(89,0 \%)$ ou os trabalhadores da rampa $(81,0 \%)$. Para os últimos, a preferência decorre dos rendimentos e da maior flexibilidade para a escolha do tempo de trabalho. Já entre os cooperados, tal preferência se deve ao fato de que as condições de trabalho na cooperativa, em comparação com as da rampa, são melhores em relação a aspectos como: esteira com cobertura propiciando maior proteção contra o sol e a chuva; jornada de trabalho menor com horário regular; existência de refeitório e vestiário para trocarem de roupa e tomarem banho; distribuição de equipamentos de proteção individual; existência de mecanismos de proteção social, como seguro-salário para o caso de acidentes e problemas de saúde, além de sua inscrição como autônomos na Previdência Social. Dispondo de um rendimento mensal regular e devidamente registrado através de um contracheque, os cooperados contam também com um comprovante que podem utilizar ao realizarem compras a crédito. Além disso, um convênio com o Serviço Social da Indústria propicia seu acesso a atividades no campo do esporte e lazer, além de atendimento médico, odontológico e psicossocial.

Os catadores apontaram o plástico - garrafas de refrigerantes - como o material reciclável que mais recolhem $(50,4 \%)$, seguido de metal $(21,1 \%)$ e papel e papelão $(16,0 \%)$. Esses percentuais se modificam quando a pergunta é sobre o tipo de material que proporciona maior fonte de renda, com o metal $(34,4 \%)$ se aproximando do plástico $(38,9 \%)$. A maioria dos pesquisados $(85,2 \%)$ destina a maior parte de seu rendimento mensal à alimentação. Ainda assim, 42,3\% mencionaram consumir alimentos achados no próprio aterro, alimentos esses provenientes, em sua maioria, de grandes supermercados, tendo suas datas de validade vencidas.

\section{Problemas ambientais, de saúde}

e morbidade referida

Caso consideremos, como muitos dos entrevistados, que ter saúde é poder trabalhar, poderíamos supor que a saúde dos catadores vai bem. Isso porque relatam dificilmente faltar ao trabalho, com muitas horas diárias dedicadas à catação, principalmente para os trabalhadores da rampa, que alternam turnos ou seguem direto, após uma pequena pausa, nos períodos da manhã e da tarde. Entretanto, outros aspectos precisam ser considerados, a começar pela própria situação de se trabalhar em um aterro e residir em suas proximidades.

Apenas 27,4\% dos entrevistados acham que o aterro gera problemas ambientais, embora haja aqui uma grande diferença de percepção entre os trabalhadores da cooperativa $(51,7 \%) \mathrm{e}$ os da rampa (24,2\%). Alguns se referiram à contaminação ambiental no manguezal e na Baía de Guanabara, outros destacaram problemas em seu bairro e ambiente de trabalho, apontando questões como a sujeira, a poeira, o cheiro forte e o risco de contaminações variadas, tanto pela presença de moscas, mosquitos e ratos, quanto pelo gás oriundo do lixo. Apesar disso, apenas uma pequena parte $(20,1 \%)$ referiu ter tido alguma doença nos últimos 15 dias ou 6 meses antes do período de realização das entrevistas, mas aqui a diferença entre cooperados $(42,8 \%)$ e trabalhadores de rampa $(16,7 \%)$ é também expressiva. Além de serem mais jovens, uma possível explicação para isso reside no fato dos trabalhadores da rampa não possuírem nenhuma proteção quando afastados por problemas de saúde, considerando como doenças somente as situações mais críticas que os impedem de ir ao trabalho. Entre as doenças referidas contraídas nesse período, destacaram-se as gripes e resfriados $(24,4 \%)$; dores e problemas osteoarticulares $(17,7 \%)$; pressão alta $(14,4 \%)$; problemas respiratórios $(10,0 \%)$, além de outras com menores índices como é o caso de acidentes, doenças de "nervo", dores estomacais e problemas cardíacos. Vale ainda registrar a presença de um caso de hanseníase, que a pessoa entrevistada afirmou ter sido adquirida no local de trabalho. Na literatura consultada, não há, porém, nenhuma referência que faça tal associação.

Em relação às doenças já contraídas em algum momento do passado, os entrevistados apontaram principalmente os resfriados $(88,1 \%)$, conjuntivite $(45,6 \%)$, dengue $(23,3 \%)$, verminoses $(22,3 \%)$, alergias $(11,9 \%)$, problemas dermatológicos $(11,4 \%)$. Além disso, foram mencionadas asma, doenças sexualmente transmissíveis, hepatite, tuberculose e cólera. 
No período das entrevistas, os catadores citaram um total de 94 doenças que possuíam naquele momento, sendo enfatizadas as seguintes: hipertensão $(31,1 \%)$, varizes $(20,2 \%)$, problemas osteoarticulares $(13,8 \%)$, problemas cardíacos $(9,6 \%)$, asma $(4,2 \%)$ e diabetes $(3,2 \%)$. Já no que se refere aos sintomas que aparecem com maior freqüência em seu dia-a-dia, houve uma grande diversificação de respostas, embora apresentando estreita relação com algumas das doenças anteriormente referidas. A Figura 5 mostra a freqüência dos principais sintomas referidos pelos entrevistados no momento da entrevista.

Embora a maioria dos trabalhadores reconheça a existência de algum risco no local de trabalho $(71,7 \%)$, apenas $47,5 \%$ acham que esses riscos podem causar problemas de saúde. É interessante observar que, apesar da potencial relação mencionada por vários autores 1,2,3 entre os riscos existentes no local de trabalho e várias das doenças e sintomas mencionados pelos entrevistados, apenas uma pequena parte dos catadores $(12,8 \%$ do total) considera que já teve alguma doença provocada pelo trabalho com o lixo, sendo esse número baixo tanto para os cooperados $(17,8 \%)$ quanto para os trabalhadores da rampa (12,0\%). Dentre os que responderam afirmativamente, destacaram-se os problemas de pele $(21,4 \%)$, os acidentes $(17,8 \%)$, problemas respiratórios $(14,3 \%)$ e outros como pneumonia, problemas de coluna, alergia, dor de cabeça, desidratação, dor de estômago, hanseníase, hepatite, leptospirose, pressão alta e "problemas de nervo".

Embora muitos neguem a relação do trabalho com as doenças e os sintomas referidos, quando o tema diz respeito aos acidentes ocorridos no aterro, a maioria $(71,7 \%)$ mencionou já ter se acidentado. Dentre os 267 casos de acidentes mencionados, destacam-se os cortes com vidros (100), as perfurações com outros materiais (50), as quedas (40), as topadas (34), a contusão por objetos na cabeça (25), as queimaduras (12) e os atropelamentos (6). No caso dos acidentes, a principal diferença entre a cooperativa e a rampa consiste na menor freqüência dentro do primeiro grupo de topadas, contusão por queda de objetos na cabeça e atropelamentos, que ocorrem apenas na rampa. Apesar da baixa freqüência, o atropelamento deve ser considerado um grave problema, tendo a circulação de catadores junto a caminhões e tratores pesados em movimento já provocado acidentes fatais no passado.

A quase totalidade dos catadores costuma recorrer a algum equipamento de proteção. A

Figura 5

Principais sintomas referidos pelos dos catadores do aterro de Gramacho.

Município de Duque de Caxias, Rio de Janeiro, Brasil.

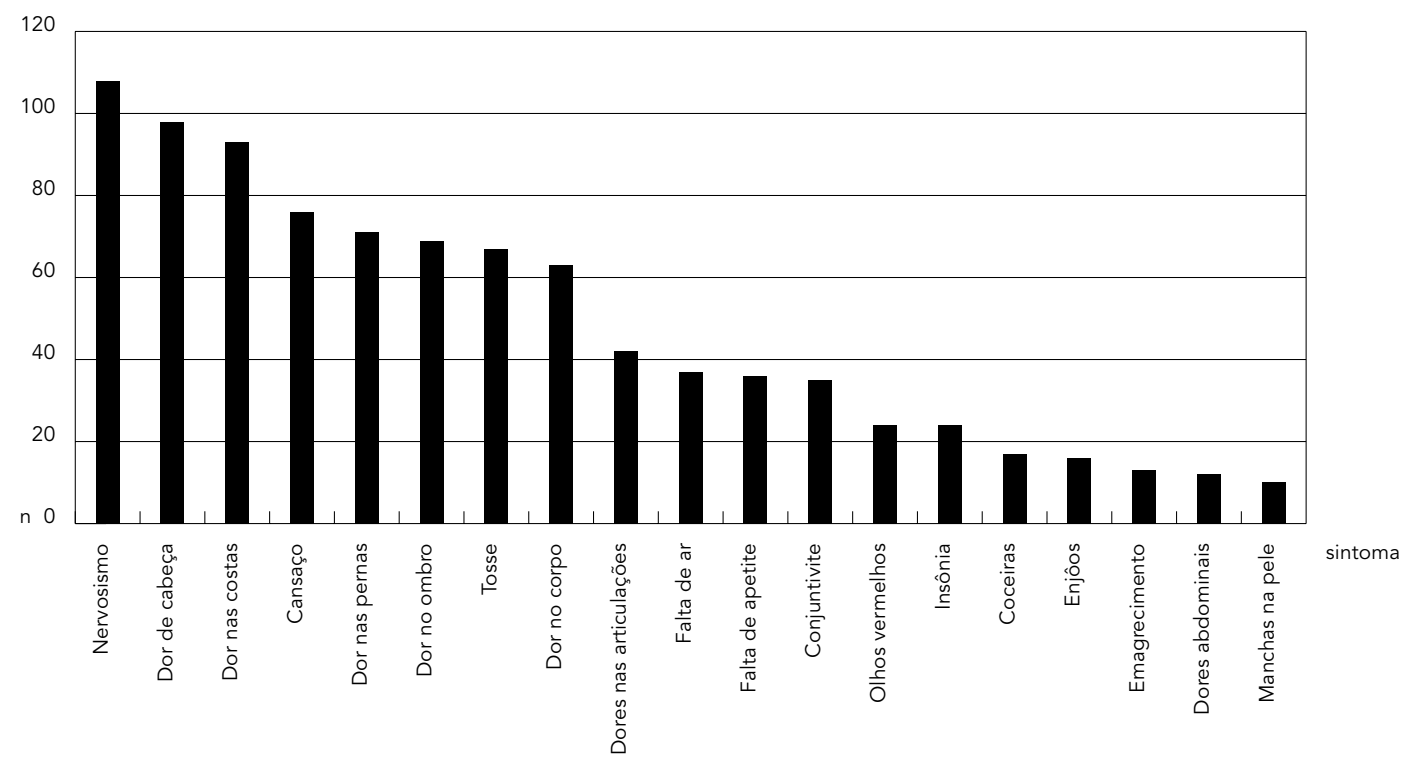


luva foi o que recebeu destaque: $76,7 \%$ dos trabalhadores a usam. Logo em seguida, apareceram o chapéu $(74,4 \%)$, as botas $(66,2 \%)$, algum tipo de proteção improvisada para as pernas e braços $(64,4 \%$ e $26,0 \%$ respectivamente), aventais $(6,4 \%)$ e máscaras $(0,9 \%)$.

Os serviços do SUS - posto de saúde ou o hospital municipal - são os locais procurados por $89,3 \%$ dos catadores quando apresentam algum problema de saúde. Apenas uma pequena parte busca outras alternativas, tais como farmácia local, consultórios particulares e amigos ou parentes. Um aspecto relevante da saúde feminina entre as trabalhadoras entrevistadas refere-se ao elevado número de mulheres que já trabalharam grávidas no aterro $(43,5 \%)$, sendo que algumas delas repetidas vezes (até oito). Das catadoras que trabalharam grávidas, $21,2 \%$ mencionaram ter tido aborto espontâneo nessa época.

Outro problema mencionado refere-se ao consumo de bebida alcoólica: $79,8 \%$ dos entrevistados reconhecem que seus colegas bebem, apesar de apenas $31,6 \%$ assumirem o consumo freqüente de bebidas. No conjunto, $31,6 \%$ afirmam que a bebida provoca algum tipo de problema no trabalho do aterro.

\section{Perspectivas de vida:}

dificuldades, melhorias e sonhos

Segundo a percepção de 48,5\% dos catadores, sua vida melhorou nos últimos cinco anos, enquanto que $34,1 \%$ não observaram alterações, e apenas $17,3 \%$ queixaram-se de terem piorado. Esses números são similares entre os trabalhadores da rampa e da cooperativa, com diferença importante apenas no item que consideram ter piorado (menor na cooperativa). Quem reconheceu alguma melhoria se referiu, em geral, à possibilidade de continuar trabalhando e com isso poder manter a família, além de consertar ou adquirir "umas coisas" para sua casa. Eles se lembraram também que alguns filhos estão estudando, e outros conseguiram um emprego, e isso foi bastante valorizado.

Já os que disseram que sua vida piorou referiram-se a um emprego perdido e à necessidade de ingresso no lixo, a problemas de saúde que apareceram, a casa cuja construção não conseguiram concluir, ao dinheiro que recebem e nunca é suficiente para suprir suas necessidades, levando-os a afirmar: "trabalho muito, mas nada dá certo”. Vários (31,0\%) foram também os que mencionaram problemas com preconceitos decorrentes do fato de trabalharem no lixo, de serem da raça negra, ou ainda carregarem o rótulo de pobres.
Apesar das dificuldades que têm enfrentado, muitos $(91,3 \%)$ foram ainda os catadores que disseram ter sonhos. Ter uma casa melhor foi o que recebeu maior destaque, entendendo-se que "melhor" inclui não só o material utilizado em sua construção, mas também sua localização e condições para equipá-la adequadamente. Outros sonhos também apareceram, como a possibilidade de sair do aterro, de conseguir um emprego "com carteira assina$d a$ ", ou mesmo melhorar de vida para poder ajudar mais pessoas da família. Se os sonhos permanecem, o mesmo não acontece com a crença nas possibilidades para realizá-los. Isso porque admitiram que seu "esforço próprio", em geral, não é suficiente para tanto. Nem sempre se referiram a sugestões para a implementação de melhorias em seu trabalho e em suas vidas, mas, quando o fizeram, apontaram essencialmente três fatores: (1) a organização da comunidade para provocar mudanças na infraestrutura do bairro onde residem; (2) alterações na rotina da rampa, com a promoção de melhorias nas condições de exercício do trabalho de catação; (3) dinamização da cooperativa, revendo sua estrutura de funcionamento.

\section{Discussão final}

Apesar das suas características exploratórias e qualitativas, o presente estudo aponta para a existência de problemas comuns entre os catadores do Aterro Metropolitano do Jardim Gramacho e outros trabalhadores brasileiros em atividades insalubres e precarizadas. Alguns aspectos, porém, os distinguem, tendo em vista o tipo de trabalho que realizam e as condições em que o mesmo é exercido, acarretando problemas adicionais. Os catadores entrevistados percebem o lixo como fonte de sobrevivência, a saúde como capacidade para o trabalho e, portanto, tendem a negar a relação direta entre o trabalho e problemas de saúde. Se a associação automática entre lixo e doença é pouco reconhecida, não há como se ignorar que inúmeros são os riscos realmente existentes no trabalho de catação, riscos esses que podem ser exemplificados através dos acidentes relatados durante a pesquisa, podendo gerar lesões permanentes ou mesmo óbitos. A disponibilidade de equipamentos de proteção adequados, bem como a conscientização sobre a importância de seu uso talvez pudesse contribuir para minimizar alguns destes acidentes, como cortes, perfurações e contusões diversas. Importantes medidas coletivas de proteção e higiene poderiam também ser adotadas, em 
especial no caso do trabalho na rampa, como é o caso do uso de sinal sonoro dos tratores quando esses engrenam a marcha a ré, alertando os catadores da existência de perigo iminente, medida essa que funcionava apenas em uma parcela dos tratores em uso na época da pesquisa.

Em relação aos demais problemas de saúde e sintomas referidos pelos entrevistados, o objetivo e o caráter mais qualitativo do estudo não permitem realizar inferências mais significativas sobre o grau de insalubridade desses catadores em comparação com outras atividades. Contudo, não há como deixar de considerar a forte carga física no trabalho e a própria rotina de serviço, fatores esses que podem estar associados tanto às dores corporais, quanto aos citados problemas osteoarticulares e à hipertensão ou "nervosismo". Assim como na questão dos acidentes, aqui também se destaca a importância de uma atuação preventiva específica, com acompanhamento periódico junto aos postos de saúde. A construção de parcerias com instituições locais, como o SUS, dirigindo a atenção às prioridades identificadas, talvez possa ser a maneira mais direta de um enfrentamento eficaz desses problemas. Não deixa de chamar atenção a baixa menção às doenças tipicamente relacionadas com o lixo, como diarréias, parasitoses, doenças de pele e leptospirose, dentre outras 1,2,3. Esse resultado precisaria ser melhor investigado futuramente, embora outros trabalhos 19,20 também mencionem uma prevalência menor que a esperada de problemas de saúde em trabalhadores que manipulam lixo, contrariando as expectativas para um ambiente tão insalubre. Uma possível hipótese explicativa para isso residiria na capacidade adaptativa dos trabalhadores existentes, os quais possuem uma média de anos de trabalho no aterro razoavelmente elevada (dez anos). É provável que muitas pessoas que lá começaram a trabalhar e desenvolveram problemas de saúde recorrentes ou graves devido às condições laborais não tenham permanecido no local.

Sem dúvida as condições de trabalho mais problemáticas se encontram na rampa, onde o trabalho a céu aberto e a circulação permanente no meio do lixo vazado entre caminhões e tratores acarretam riscos sérios para a saúde. Apesar desses riscos mais graves, são justamente os trabalhadores da rampa os mais desprotegidos devido às peculiaridades de sua história e organização. Não existe nenhuma instância coletiva ou institucional responsável por esses trabalhadores, e qualquer iniciativa nesse sentido é vista como incentivo à sua permanência no local, o que contrariaria as premis- sas de gerenciamento adequado de um aterro sanitário ou controlado de resíduos.

O paradoxo entre uma premissa técnicogerencial e uma decisão política assumida de tolerar tal situação gerou, na prática, um vazio de responsabilidades e uma tendência paralisante quanto à implementação de possíveis medidas que melhorassem as condições de trabalho dos catadores da rampa. Juntam-se a esse problema outras dificuldades, como o número elevado de pessoas que trabalham na rampa, a inexistência de fóruns de discussão coletiva, a relação mantida com os depósitos e com outras forças locais, incluindo a suspeita da presença do narcotráfico na região eventualmente expressa por receosas meias palavras. Já entre os cooperados, as ações talvez possam ser mais facilmente agilizadas, levando-se em conta tanto o fato de se constituírem em um número menor, quanto o nível de organização já existente e que poderá ser fortalecido, expandindo-se aos demais catadores. Para o desenvolvimento de ações em ambos os casos, é necessário, contudo, se identificar as diretrizes e/ou políticas já implantadas no município, somando esforços para se otimizar sua operacionalização.

Envolver efetivamente os catadores em qualquer processo de mudança é um dos aspectos que consideramos como fundamental para o alcance de qualquer melhoria em suas condições de saúde, vida e trabalho. E esse envolvimento deve ter como ponto de partida o investimento em discussões relativas à cidadania e à auto-estima, já que vários foram os catadores que se juntaram ao depoimento que ouvimos: "nós somos tratados como os que precisam de ajuda, de salvação e têm uns que acham que não somos gente... Aqui nós somos seres humanos diferentes ... Nossa esperança aqui só existe de dois jeitos: pela força do nosso trabalho com os amigos que tão no mesmo barco ou de Deus" (Diário de campo, julho de 2001). Se não forem reconhecidos e se reconhecerem como sujeitos com direitos e deveres, bem como se não conseguirem enfrentar os estigmas que cercam a atividade de catador de materiais recicláveis, dificilmente eles se envolverão integralmente em qualquer iniciativa que venha a ser proposta, continuando a apontar dificuldades, sem acreditar em possíveis saídas, ou então esperando que as resoluções sejam promovidas por "terceiros" ou por obra de algum milagre divino. Por outro lado, as instituições envolvidas - ambientais, sociais e sanitárias também deveriam mudar seus paradigmas para aceitar a realidade desses catadores como ponto de partida para a sua transformação. 
Conhecer de perto experiências vividas por outros trabalhadores de diferentes cidades brasileiras poderá também consistir em um estímulo a mais para os catadores repensarem o cotidiano em que vivem e aquele que serão capazes de construir, mobilizando não só o poder público, mas também outros recursos locais. A existência de várias experiências de sucesso com coleta seletiva de lixo em diversos municípios brasileiros, e que contaram com a organização de catadores em diferentes estruturas envolvendo parcerias com o poder público e privado, ONGs ambientais e a população, vem demonstrando a viabilidade de se articular problemas ambientais e de saúde pública com cidadania, resultando na melhoria das condições de vida e trabalho desse grupo social. Essas experiências poderiam servir de base para a discussão de alternativas futuras dos catadores de Jardim Gramacho, que se tornam ainda mais importantes em função da proximidade do possível fechamento desse aterro em decorrência do esgotamento de sua vida útil.

Com tais considerações, nossa avaliação é a de que propostas que operem com paradigmas isolados, ainda que bem-intencionados, tenderão a reproduzir erros no encaminhamento de políticas e ações que visem resolver o pro- blema. A questão é envolver os catadores com diferentes parceiros, considerando, sobretudo, que a problemática do lixo deve ser vista de forma integrada em suas múltiplas dimensões, não se esquecendo que existe uma cadeia produtiva em movimento e nela o catador tem um papel a desempenhar. Papel que ainda é desvalorizado pela sociedade, aproveitando-se disso os próprios agentes do circuito econômico da reciclagem - comerciantes e atravessadores de sucata, além das próprias indústrias - para aprofundar as formas de exploração dos catadores em condições extremamente precárias e informais de trabalho e remuneração.

Contudo, nas fronteiras da exclusão e da precariedade, esse grupo atua de forma silenciosa e vem lentamente se organizando em associações, cooperativas e busca ter seus direitos reconhecidos 21 , o que pode ser constatado pela recente inclusão da ocupação catador de material reciclável na nova Classificação Brasileira de Ocupações de 2002. Tal perspectiva, se compreendida dentro da complexidade que envolve o tema, pode apontar para o resgate da dignidade de tais trabalhadores, inserindo-os no âmbito das políticas públicas abrangentes que integrem simultaneamente necessidades sociais, ambientais e de saúde pública.

\section{Resumo}

Este artigo apresenta os resultados de uma investigação sobre condições de vida, trabalho e saúde envolvendo 218 catadores de materiais recicláveis atuando no aterro metropolitano do Rio de Janeiro, Brasil. Recorrendo a um inquérito semi-estruturado, a pesquisa ouviu tais sujeitos sobre seu cotidiano e as percepções acerca de suas condições de vida, trabalho e saúde. Através de uma análise quanti-qualitativa, identificou-se que os catadores entrevistados percebem o lixo como fonte de sobrevivência, a saúde como capacidade para o trabalho e, portanto, tendem a negar a relação direta entre o trabalho e problemas de saúde. Contudo, os riscos levantados e a morbidade referida apontam para a elevada insalubridade e periculosidade dessa atividade, agravadas, possivelmente, pelas condições de vida que apresentam, inclusive no que se refere aos locais de moradia. Ao final, o artigo sugere a construção de políticas públicas que integrem diferentes dimensões do problema, como inclusão social, preservação ambiental, saúde pública e o resgate da dignidade desses trabalhadores.

Lixo; Saúde Ocupacional; Condições de Trabalho

\section{Colaboradores}

M. F. S. Porto redigiu o texto completo do artigo, em colaboração com as demais autoras. D. C. M. Juncá e R. S. Gonçalves colaboraram em todas as etapas do desenvolvimento da pesquisa, sendo que a primeira foi a principal responsável pela revisão final do artigo. M. I. F. Filhote colaborou especificamente na preparação do inquérito de morbidade e posterior aplicação de testes pilotos que levaram ao seu aperfeiçoamento.

\section{Agradecimentos}

Os autores agradecem aos pesquisadores de campo, Luiz dos Santos Costa, Tânia Maria Moraes Alves e Wânia Borges Nepomuceno, por sua dedicação em condições de trabalho particularmente difíceis. Agradecemos também as contribuições em diversas etapas do projeto de Cristina Sisinno e João Alberto Ferreira, especialistas na temática dos resíduos sólidos, e de Márcia Agostini e José Cláudio da Costa Barros. 


\section{Referências}

1. Catapreta CAN, Heller L. Associação entre coleta de resíduos sólidos domiciliares e saúde, Belo Horizonte (MG), Brasil. Rev Panam Salud Publica 1999; 5:88-96

2. Ferreira JA, Anjos LA. Aspectos de saúde coletiva e ocupacional associados à gestão dos resíduos sólidos municipais. Cad Saúde Pública 2001; 17:689-96.

3. Sisinno CLS, Oliveira RM, organizadores. Resíduos sólidos, ambiente e saúde: uma visão multidisciplinar. Rio de Janeiro: Editora Fiocruz; 2000.

4. Almeida LP, Martins LFS, Brod CS, Germano PML. Levantamento soroepidemiológico de leptospirose em trabalhadores do serviço de saneamento ambiental em localidade urbana da região Sul do Brasil. Rev Saúde Pública 1994; 28:76-81.

5. Velloso MP, Santos EM, Anjos LA. Processo de trabalho e acidentes de trabalho em coletores de lixo domiciliar na cidade do Rio de Janeiro, Brasil. Cad Saúde Pública 1997; 13:693-700.

6. Barcellos C, Sabroza PC. The place behind the case: leptospirosis risks and associated environmental conditions in a flood-related outbreak in Rio de Janeiro. Cad Saúde Pública 2001; 17:59-67.

7. Escorel S. Vidas ao léu: trajetórias de exclusão social. Rio de Janeiro: Editora Fiocruz; 1999.

8. Neri M, Soares W. Desigualdade social e saúde no Brasil. Cad Saúde Pública 2002; 18:77-87.

9. Araújo LMS. Trabalho, sociabilidade e exclusão social: o caso dos bagulhadores do Lixão de Aguazinha [Dissertação de Mestrado]. Recife: Universidade Federal de Pernambuco; 1997.

10. Portilho MFF. Profissionais do lixo: um estudo sobre as representações sociais de engenheiros, garis e catadores [Dissertação de Mestrado]. Rio de Janeiro: Universidade Federal do Rio de Janeiro; 1997.
11. Escurra MF. Sobrevivendo do lixo: população excedente, trabalho e pobreza [Dissertação de Mestrado]. Rio de Janeiro: Universidade Federal do Rio de Janeiro; 1997.

12. Azeredo VG. Os recicladores da miséria [Dissertação de Mestrado]. Rio de Janeiro: Universidade Federal do Rio de Janeiro; 1999.

13. Grossi G. Os badameiros: a descoberta do lixo. Cadernos do Centro de Estudos e Ação Social, Salvador 1999; 182:67-84.

14. Juncá DCM, Gonçalves MP, Azevedo VG. A mão que obra no lixo. Niterói: EdUFF; 2000.

15. Muñoz JV, organizador. O catador de papel e o mundo do trabalho. Rio de Janeiro: Nova; 2000.

16. Magera M. Os empresários do lixo: um paradoxo da modernidade. Campinas: Átomo; 2003.

17. Weber W. Despoluição da Baía de Guanabara: saneamento básico para 5 milhões de habitantes. Revista da FEEMA 1995; 17:41-8.

18. Costa-e-Silva CAM. Situação do aterro metropolitano de resíduos urbanos [Monografia de Especialização]. Rio de Janeiro: Universidade Estácio de Sá; 1994.

19. Leite FSS, Rocha LL, Venâncio AM, Ptak M, Cardoso MAC. Impacto na saúde dos catadores do Lixão da Terra Dura e estudo gravimétrico. Bio: Revista Brasileira de Saneamento e Meio Ambiente 1990; 2:48-51.

20. Zanon U. O desperdício na assistência à saúde. In: Eigenheer E, organizador. Raízes do desperdício. Rio de Janeiro: Iser; 1993. p. 73-82.

21. Magalhães T. A reação dos excluídos. Bio: Revista Brasileira de Saneamento e Meio Ambiente 2000; 11:14-9.

Recebido em 12/Jan/2004

Versão final reapresentada em $07 / \mathrm{Jun} / 2004$ Aprovado em 22/Jun/2004 